\title{
SMS Deposit Size and Abundance - Mining Districts and the Ore System Concept: The INDEX Seafloor Sulfide Perspective
}

\author{
U. SCHWARZ-SCHAMPERA ${ }^{1}$, H. GIBSON ${ }^{2}$, M. \\ KLISCHIES $^{3}$, R. FREITAG ${ }^{1}$ \\ ${ }^{1}$ Federal Institute for Geosciences and Natural Resources \\ (BGR), D-30655 Hannover, Germany \\ ${ }^{2}$ Laurentian University Sudbury, Canada \\ ${ }^{3}$ Helmholz Center for Ocean Research Kiel, D-24148 Kiel,
} Germany

Ancient VMS deposits, regardless of age and geodynamic environment, occur in clusters referred to as districts, which are defined by the restricted areal distribution of the deposits, and the limits of the volcanic/structural feature that is host to the deposits. Examples include the Archean Noranda and Matagami Districts, the Paleoproterozoic Flin Flon and Snow Lake Districts, and the Miocene Hokuroku Districts. Within a district, VMS deposits can differ in base and precious metal grade, size, host rocks, alteration type, and deposit-scale environment. They share a close spatial association (10's of $\mathrm{km}$ ), and a location at specific time-stratigraphic intervals within the host volcanic successions. The latter indicates that VMS deposits repeatedly form during specific intervals in the evolution of specific larger volcanic complexes. A VMS district scale requires an entirely different perspective on ore forming processes and exploration criteria.

The VMS district concept is applied to MOR SMS deposits at the CIR and SEIR, identified during the INDEX exploration program. The claim area covers different ridge segments. The bathymetry of each segment may differ, but within each segment there is a central large axial volcano and /or significant syn- and post-volcanic uplift concentrated to the central area of the segment due to post volcanic magmatic and structural doming. The bathymetric high areas define "volcanic complexes" that host 10 SMS districts as yet identified. The SMS deposits fall within a modest $20 \mathrm{~km}$ district diameter. Thus, like VMS deposits, SMS deposits can viewed as forming within districts, to be products of large, district-scale, ore systems. Variations in the grade, size, alteration, host lithofacies and environment within a district and between districts are expected. The variations within and between districts reflect processes operating at different scales within the MOR ore system. The identification of district-scale ore-forming features and processes are the central scientific aim of the ongoing INDEX exploration program. 